\title{
Use of antiepileptic drugs during pregnancy and risk of spontaneous abortion and stillbirth: population based cohort study
}

\author{
OPEN ACCESS
}

\author{
Bodil Hammer Bech associate professor ${ }^{1}$, Maiken Ina Siegismund Kjaersgaard PhD student ${ }^{2}$, Henrik \\ Søndergaard Pedersen statistician ${ }^{3}$, Penelope P Howards assistant professor ${ }^{4}$, Merete Juul Sørensen \\ consultant $^{5}$, Jørn Olsen professor ${ }^{1}$, Erik Thorlund Parner professor ${ }^{2}$, Lars Henning Pedersen adjunct \\ associate professor $^{16}$, Mogens Vestergaard professor ${ }^{3}$, Jakob Christensen senior registrar ${ }^{78}$
}

${ }^{1}$ Section for Epidemiology, Department of Public Health, Aarhus University, DK 8000 Aarhus C, Denmark; ${ }^{2}$ Section for Biostatistics, Department of Public Health, Aarhus University, Aarhus, Denmark; ${ }^{3}$ Research Unit for General Practice and Section for General Medical Practice, Department of Public Health, Aarhus University, Aarhus, Denmark; ${ }^{4}$ Department of Epidemiology, Rollins School of Public Health, Atlanta, GA, USA; ${ }^{5}$ Regional Center of Child and Adolescent Psychiatry, Aarhus University Hospital, Risskov, Denmark; ${ }^{6}$ Department of Clinical Medicine-Obstetrics and Gynaecology, Aarhus University, Aarhus, Denmark; ${ }^{7}$ Department of Neurology, Aarhus University Hospital, Aarhus, Denmark; ${ }^{8}$ Department of Clinical Pharmacology, Aarhus University Hospital, Aarhus, Denmark

\begin{abstract}
Objective To determine whether use of antiepileptic drugs during pregnancy may increase the risk of spontaneous abortion or stillbirth.

Design Population based cohort study.

Setting Register based study in Denmark, 1997-2008.

Participants 983305 pregnancies identified in the Danish medical birth register and the Danish national hospital discharge register from 1 February 1997 to 31 December 2008 were linked to the Danish Register of Medicinal Product Statistics to obtain information on use of antiepileptic drugs.
\end{abstract}

Main outcome measures Risk ratio of spontaneous abortion and stillbirth after use of antiepileptic drugs during pregnancy, estimated by using binomial regression adjusting for potential confounders of maternal age, cohabitation, income, education, history of severe mental disorder, and history of drug misuse.

Results Antiepileptic drugs were used in a total of 4700 (0.5\%) pregnancies. 16 out of 100 pregnant women using antiepileptics and 13 out of 100 pregnant women not using antiepileptics experienced a spontaneous abortion. After adjusting for potential confounders pregnant women using antiepileptics had a $13 \%$ higher risk of spontaneous abortions than pregnant women not using antiepileptics (adjusted risk ratio $1.13,95 \%$ confidence interval 1.04 to 1.24 ). However, the risk of spontaneous abortion was not increased in women with an epilepsy diagnosis $(0.98,0.87$ to 1.09$)$, only in women without a diagnosis of epilepsy $(1.30,1.14$ to 1.49$)$. In an analysis including women with at least two pregnancies with discordant antiepileptic drug use (for example, use in the first pregnancy but not in the second), the adjusted hazard ratio for spontaneous abortion was $0.83(0.69$ to 1.00$)$ for exposed pregnancies compared with unexposed pregnancies. Stillbirth was identified in 18 women who used antiepileptic drugs (unadjusted risk ratio $1.29,0.80$ to 2.10$)$.

Conclusion Among women with epilepsy and when analysing the risk in antiepileptic drug discordant pregnancies in the same woman, we found no overall association between the use of antiepileptic drugs during pregnancy and spontaneous abortions. Therefore unmeasured confounding may explain the slight increased risk for spontaneous abortion with any antiepileptic drug use (among women both with and without epilepsy). We found no association between antiepileptic drug use during pregnancy and stillbirth, but the statistical precision was low.

\section{Introduction}

Epilepsy affects $0.3-0.8 \%$ of pregnant women, making it the most common neurological disorder requiring medical treatment during pregnancy. ${ }^{12}$ Treatment must balance the risk of seizures with the potential for adverse effects from drug use. ${ }^{3}$ Antiepileptic drugs are also commonly used for psychiatric disorders, pain disorders, and migraines.

A recent study from the United States found that antiepileptic drug use during pregnancy is increasing, especially for the newer drugs. ${ }^{4}$ In Denmark, the use of the newer drugs during pregnancy has also increased, but this trend has been counterbalanced by a decrease in the use of the older drugs; in combination, this has resulted in an unchanged total use of antiepileptics. ${ }^{5}$ Use of antiepileptic drugs during pregnancy has been associated with 
pregnancy complications, including pre-eclampsia, bleeding, preterm birth, intrauterine growth retardation, and fetal malformations. ${ }^{16}$ However, little is known about the association between antiepileptics and spontaneous abortion or stillbirth. In animal studies, a dose dependent increased risk of fetal death has been observed after use of antiepileptics. ${ }^{78}$ Human studies are conflicting; some reported twice the risk of fetal death in exposed compared with unexposed pregnancies, whereas other studies found no association. ${ }^{9-15}$

We conducted a large population based cohort study to investigate the association between maternal antiepileptic drug use during pregnancy and spontaneous abortion and stillbirth, after taking potential confounders into account. In addition, we compared the risk of spontaneous abortion in women with more than one pregnancy and discordant antiepileptic drug use across pregnancies (for example, use in the first pregnancy but not in the second) in an attempt to adjust for unmeasured shared environmental and familial factors.

\section{Methods}

\section{Study population}

In Denmark all citizens are assigned a unique personal identification number at birth. We used this number to link information across national health registers and to identify all clinically recognised pregnancies with an estimated date of conception and a known pregnancy outcome from 1 February 1997 to 31 December 2008. Linkage is close to $100 \%$ as the unique personal identification number is almost always correctly reported. ${ }^{16}$ The Danish medical birth registry includes information on all live births and stillbirths in Denmark since 1973. ${ }^{17}$ We identified other pregnancy outcomes (for example, spontaneous abortions) in the Danish national hospital discharge register, which contains information on treatments at hospitals in Denmark since 1977 and outpatient contacts since 1995. ${ }^{18}$ Diagnoses are classified based on the WHO international classification of diseases (ICD-8 codes for the years 1977-93 and ICD-10 from 1994 and onwards).

\section{Pregnancy outcomes}

We used the following ICD-10 diagnoses: spontaneous abortions (O02.0-O03.9), induced abortions (O04.0-O05.2, O05.5-O06.9), induced abortion because of heredity (O05.3), and induced abortion because of malformation of the fetus (O05.4). Molar $(\mathrm{O} 01)$ and ectopic pregnancies $(\mathrm{O} 00)$ were excluded. Some women had more than one ICD-10 diagnosis for the same pregnancy. Pregnancy was classified according to a predetermined algorithm. We prioritised live birth and stillbirth codes over spontaneous and induced abortion codes, and spontaneous abortion over induced abortion.

Gestational age was obtained from the Danish medical birth register for live births and stillbirths and from the Danish national hospital discharge register for abortions. We excluded women with missing information on gestational age (2.19\%). The first day of the last menstrual period was estimated by subtracting gestational age from the date of pregnancy termination. Before 1 January 2004, stillbirth in Denmark was defined as birth of a dead fetus after 28 completed gestational weeks or later, but in 2004 the cut point was changed to 22 completed weeks. We coded all fetal deaths between 22 and 28 completed weeks as stillbirths.

\section{Use of antiepileptic drugs}

In Denmark, antiepileptic drugs are supplied by prescription. The Danish Register of Medicinal Product Statistics comprises records of all prescriptions redeemed since 1 January 1996. However, treatment given only during inpatient hospital admission is not recorded. We defined the use of antiepileptic drugs as any prescription redeemed with the Anatomical Therapeutic Chemical codes N03A (antiepileptic drugs) or N05BA09 (clobazam).

Based on information about the dates of prescriptions filled and the number of pills and dose for each prescription, we calculated the cumulative dose of antiepileptic drugs used during the exposure window. To estimate the average daily dose we divided the cumulative dose by the number of days in the exposure window. Based on the defined daily dose, ${ }^{19}$ we dichotomised the estimated daily antiepileptic drug dose into high ( $>50 \%$ of defined daily dose) or low ( $\leq 50 \%$ of defined daily dose).

\section{Diagnostic and covariate information}

From the Danish national hospital discharge register we identified women with a diagnosis of epilepsy (ICD-8: 345; ICD-10: G40 and G41) before the end of the index pregnancy. We used the Danish psychiatric central research register ${ }^{20}$ to identify mothers with a diagnosis of the following psychiatric disorders before the end of the index pregnancy: substance abuse (ICD-8: 291, 294.3, 303, 304; ICD-10: F10-F19), depression (ICD-8: 296.0, 298.0, 300.4; ICD10: F32-F33), and severe psychiatric disorders (ICD-8: 296.1-296.8, 298.1 and 295; ICD-10: F30-F31 and F20).

From Statistics Denmark we obtained information on maternal age, cohabitation, income, and education at the time of the index pregnancy.

\section{Statistical analysis}

We fitted a generalised linear model for our binary outcome (binomial distribution) with a log-link, which gives the risk ratio. The model is also called log-binomial regression. We used robust variance estimation to allow for correlations between pregnancy outcomes in each woman. Risk ratios for spontaneous abortion were adjusted for maternal age (thirds), cohabitation (yes/no), income (dichotomised at the median), education $(<10$, 10-12, >12 years), history of severe mental disorder (yes/no), and history of drug misuse (yes/no), which are known risk factors for spontaneous abortion or likely proxies for unmeasured risk factors. We excluded induced abortions from the binomial models and restricted analyses to participants with information on all variables $(n=802680)$. For the main analysis we carried out a sensitivity analysis where we used multiple imputation with 100 imputations for all missing values on antiepileptic drug use (because of missing information on gestational age) and covariates. As the results for the complete case analysis and the analysis using multiple imputation were almost identical we only show results for the complete case analyses. Adjusted analyses for stillbirth included one covariate at a time owing to the low number of exposed stillbirths. To avoid unstable results we fitted models only when at least five events were observed in each drug use group.

We estimated the risk ratios for spontaneous abortion for use of any antiepileptic drug, to the most common individual drugs (carbamazepine, clonazepam, lamotrigine, oxcarbazepine, and valproate), and to high or low doses of the drugs.

In the analyses we included all antiepileptic drug prescriptions redeemed from 1 January 1996 to 31 December 2008. For 
stillbirths, we defined the exposure window from 30 days before the estimated day of conception to the day before the end of the pregnancy. For spontaneous abortions, the exposure window ended at the gestational age of 22 weeks (152 days) or at the end of the pregnancy, whichever occurred first. Unexposed pregnancies included those where the mother did not redeem any antiepileptic drug prescription in the exposure window.

As spontaneous abortion and live birth might have a differential opportunity for exposure owing to different lengths of pregnancy, we performed a sensitivity analysis where we truncated the exposure window at 10 gestational weeks.

To estimate the effects of misclassification related to use of antiepileptics, we performed a sensitivity analysis excluding pregnancies where an antiepileptic drug prescription had been redeemed from six months to 30 days before conception but not during the index pregnancy. In another sensitivity analysis, we set the exposure window at 180 days before conception.

To reduce confounding by indication, we stratified the main analyses by "ever" versus "never" having a diagnosis of epilepsy based on the Danish national hospital discharge register. We also examined whether estimates were changed when the study population was restricted to women with a diagnosis of epilepsy during the five years before conception of the index pregnancy. Finally, we compared pregnant women who used antiepileptic drugs with pregnant women who had redeemed an antiepileptic drug prescription in the year before the index pregnancy, but not during the exposure window for the index pregnancy ( $\mathrm{n}=1553$ pregnancies).

To control for unmeasured shared environmental risk factors and genetic predisposition, we performed a stratified Cox regression analysis with robust variance estimation, including in the cohort those women who had at least two pregnancies with discordant exposure status (for example, antiepileptic use in the first but not the second pregnancy). The stratified Cox regression includes a separate stratum for each woman; thus, each woman has her own baseline rate function. The analysis included 289 women with 898 pregnancies, including 383 spontaneous abortions.

We excluded induced abortions from the main analyses. However, because an induced abortion could potentially have ended in a spontaneous abortion if the pregnancy had not been electively terminated early, we performed sensitivity analyses using Cox regression including induced abortions where the pregnancies were censored when the pregnancy was terminated.

Analyses were performed using Stata 12 statistical software (StataCorp, TX).

\section{Results}

Our study included a total of 983305 pregnancies of which 109 800 resulted in a spontaneous abortion (11\%), 3222 in stillbirths $(0.3 \%)$, and 175694 in induced abortions $(18 \%)$. We identified $4700(0.5 \%)$ pregnancies exposed to antiepileptic drugs. Table $1 \Downarrow$ shows the characteristics of the total study population.

Women who used antiepileptics were more likely to live alone, have a lower income, and have a lower education than women who did not use antiepileptics. Women who used antiepileptics also were more likely to have a history of a psychiatric disorder (including severe psychiatric disorders), substance misuse, and use of antipsychotics and antidepressants. Furthermore, induced abortions were more common among women who used than did not use antiepileptics.

In the overall analysis, pregnant women who used antiepileptics had a 13\% higher risk of spontaneous abortion (adjusted risk ratio $1.13,95 \%$ confidence interval, 1.04 to 1.22 ) compared with women who did not use antiepileptics (table $2 \Downarrow$ ). The association remained when we excluded women with a diagnosis of a severe mental disorder $(1.12,1.03$ to 1.21$)$ or women who used antidepressants, antipsychotics, or insulin $(1.09,1.00$ to 1.19). Furthermore, results remained unchanged when the exposure window was extended to six months before conception $(1.17,1.09$ to 1.25$)$ or when women who used antiepileptics from six months to 30 days before pregnancy were excluded from the unexposed group $(1.13,1.04$ to 1.22$)$. However, when we compared women who used antiepileptics during the exposure window with women who used antiepileptics in the year before conception but not during pregnancy, we found no association between antiepileptic drug use in pregnancy and risk of spontaneous abortion ( $0.90,0.79$ to 1.02$)$.

In matched analyses of consecutive pregnancies in the same woman, the adjusted hazard ratio for spontaneous abortion was 0.83 (95\% confidence interval 0.69 to 1.00 ) for pregnancies exposed to antiepileptic drugs compared with unexposed pregnancies.

When stratifying on maternal epilepsy status, we found an increased risk of spontaneous abortion for exposed women without an epilepsy diagnosis, but not for those with epilepsy (table $3 \Downarrow$ ). Ending the exposure window at 10 gestational weeks changed the estimates only a little; for women ever diagnosed with epilepsy the adjusted risk ratio for spontaneous abortion was 1.06 (95\% confidence interval 0.95 to 1.18 ) and for women without a diagnosis of epilepsy it was 1.41 (1.23 to 1.60$)$.

The most commonly used antiepileptic drugs were lamotrigine (34\%), valproate (13\%), carbamazepine (12\%), clonazepam $(11 \%)$, and oxcarbazepine (11\%). When we stratified on ever versus never having a diagnosis of epilepsy, all of these drugs were associated with spontaneous abortion in pregnant women without an epilepsy diagnosis but not in pregnant women with a diagnosis of epilepsy (table $4 \Downarrow$ ). However, a high dose of the drugs was associated with an increased unadjusted risk of spontaneous abortion in women both with and without a diagnosis of epilepsy compared with women who did not use antiepileptics (figure $\downarrow$ ).

When we used Cox regression to include induced abortions in the analysis, the hazard ratio for spontaneous abortion was almost the same (adjusted hazard ratio 1.11, 95\% confidence interval 1.02 to 1.21 ) as the risk ratio in the main analysis (binomial regression) excluding induced abortion.

The unadjusted risk ratio for stillbirth was 1.29 (95\% confidence interval 0.80 to 2.10, table 2). Adjusting for maternal age, cohabitation, income, history of severe mental disorder, or history of drug misuse one at a time changed the estimate only slightly.

\section{Discussion}

In this population based cohort study, pregnant women who took antiepileptic drugs had a small but statistically significant higher risk of spontaneous abortion than women who did not take antiepileptic drugs. However, we found no association with spontaneous abortion when restricting the analyses to women with an epilepsy diagnosis, suggesting that this association may be explained by confounding as a result of underlying disorders or their manifestations (confounding by indication). Similar results were found when exposed pregnancies were compared with pregnancies in women who had filled a prescription for an antiepileptic drug in the year before but not during pregnancy. Furthermore, use of antiepileptics did not increase the risk of spontaneous abortion across pregnancies discordant for 
antiepileptic drug use. This finding indicates that confounding from either family or lifestyle factors may explain the small increased risk in the main analysis.

We found an increased risk of stillbirth for women taking antiepileptic drugs during pregnancy, but the results were imprecise and were not statistically significant. Because stillbirths were rare ( $\mathrm{n}=18$ in women who used antiepileptics), we were unable to adjust for all covariates simultaneously. However, when we adjusted for one covariate at a time, the estimates changed only slightly.

Women who used antiepileptic drugs chose to terminate pregnancy more often than women who did not use antiepileptic drugs during pregnancy. However, the proportion of induced abortions because of fetal disease was almost the same in the exposed and unexposed group $(0.5 \%$ and $0.3 \%$, respectively, table 1). Some of the pregnancies that were terminated may have resulted in spontaneous abortion or stillbirth if the pregnancy had continued. If the risks of spontaneous abortion and stillbirth in the terminated pregnancies were different in the exposed and unexposed groups, the estimated risk of spontaneous abortion and stillbirth would be biased. However, our results did not change much when we fitted Cox regression models with induced abortions censored at termination of pregnancy.

\section{Interpretation of results and comparison with other studies}

Previous studies of spontaneous abortion and stillbirth after prenatal use of antiepileptic drugs have been conflicting. One study found that the risk of spontaneous abortion increased by more than $80 \%$ in women taking antiepileptic drugs for epilepsy compared with women without epilepsy, but the association was attenuated when compared with women with a history of epilepsy but who did not use antiepileptics. ${ }^{9}$ Another study found an increased risk of miscarriage or stillbirth in pregnant women with epilepsy using antiepileptic drugs compared with women with epilepsy who did not use antiepileptics (14\% and $4 \%$, respectively, $\mathrm{P}<0.01$ ). However, this increased risk might be explained by the frequent use of trimethadione (which is a strong teratogen) in this population..$^{21}$ Two other studies did not observe a difference in risk of spontaneous abortion and stillbirth between women with epilepsy who used antiepileptics and those who did not; however, both studies were small. ${ }^{14}{ }^{15}$

Antiepileptic drugs are also prescribed for disorders other than epilepsy, including bipolar disorder, migraine, and pain, thus allowing for confounding by indication from these disorders. For women without a diagnosis of epilepsy, we found the risk of spontaneous abortion to be $30 \%$ higher among women who used antiepileptics compared with those who did not, which may be related to the underlying disorder itself or another risk profile for these women that we were not able to adjust for in the analyses.

For women with an epilepsy diagnosis, we found no association between antiepileptic drug use and spontaneous abortion. This result does not entirely exclude the possibility of a harmful effect of antiepileptic drugs on spontaneous abortion because antiepileptic drugs may decrease the risk of seizures in pregnant women with epilepsy, and seizures might be a stronger risk factor for spontaneous abortion than use of antiepileptic drugs. Unfortunately, we had no information on the prevalence of seizures during pregnancy. However, a study of 1956 pregnancies had only 36 cases of status epilepticus ( 12 convulsive), which resulted in one stillbirth, no spontaneous abortions, and no maternal deaths. ${ }^{22}$ This suggests that seizures may not be a significant contributing factor for risk of fetal death.

Animal studies have shown a dose-dependent association between antiepileptic drug use and risk of spontaneous abortion. ${ }^{78} \mathrm{We}$ did find an increased risk of spontaneous abortion in women filling prescriptions for high doses of antiepileptic drugs for those both with and without a diagnosis of epilepsy, even after adjusting for measured confounders. This may indicate a threshold effect or could be a consequence of confounding by indication, such as severity of the disorder, or other types of confounding for which we were not able to adjust. However, in a sensitivity analysis of women exposed in the year before conception, but not during pregnancy, we still found an increased risk for women using high doses (data not shown). We did not have information on the actual antiepileptic drug dose prescribed or taken by the women, nor did we know if the dose was changed during the pregnancy, which may limit the validity of the analyses on dose-response. We have been unable to identify other studies that have analysed the risk of spontaneous abortions while accounting for antiepileptic drug dose, but published studies have found that high doses of antiepileptic drugs during pregnancy may be associated with an increased risk of congenital malformations compared with low doses. ${ }^{23} 24$

Previous studies have found valproate ${ }^{25}$ and topiramate ${ }^{11}$ to be associated with spontaneous abortion, although the results were not statistically significant. Topiramate accounted for only $5 \%$ of the antiepileptic drug use in our study population, so we did not have statistical power to analyse this drug separately.

\section{Strengths and limitations of this study}

As a result of the information available in the Danish registries, we were able to include all clinically recognised pregnancies in Denmark during a 12 year study period with almost complete follow-up. Therefore the results are not likely to be hampered by selection bias.

Information on use of antiepileptics was based on prescriptions filled for the drugs. In Denmark, antiepileptic drugs require a prescription. Although we have no information as to whether the women actually used the drugs, a previous study found that compliance was high for antiepileptic drug use among pregnant women, ${ }^{26}$ and this suggests that misclassification in our exposed group is likely to be low. Non-compliance to drug use in the exposed group could attenuate the association. We cannot rule out the possibility that some women in the unexposed group actually used antiepileptics because some may have bought antiepileptic drugs before the time of the exposure window (that is, 30 days before pregnancy). However, our results were not changed by extending the exposure window to six months before pregnancy.

We identified data on spontaneous abortions and stillbirths in Danish health registries. A previous study found a positive predictive value of $97.4 \%$ for the diagnosis "spontaneous abortion" in the Danish national hospital discharge register. ${ }^{27}$

Healthcare in Denmark is freely available to all citizens, and almost all stillbirths and spontaneous abortions after recognised pregnancy are dealt with at a hospital. However, very early spontaneous abortions may be mistaken as a late menstrual period, especially if the pregnancy was unplanned. Thus, if antiepileptic drug use increases the risk of very early unrecognised spontaneous abortions, our results may have underestimated an association between prenatal exposure and spontaneous abortions. On the other hand, if antiepileptic drug users (such as women with epilepsy) recognise their pregnancy 
at an earlier stage than women who do not use antiepileptics, then unrecognised spontaneous abortion might be more commoon in the unexposed group, which might lead to an artificially increased effect estimate. However, we found no difference in mean gestational age of spontaneous abortion for the women who did or did not use antiepileptics during pregnancy. This suggests that the time of recognition of pregnancies is not a serious source of bias in this study.

We did not find an association in the fully adjusted analyses of antiepileptic drug discordant pregnancies in the same woman, which suggests that confounding by indication and residual confounding may explain the increased risk identified in the other analyses. Despite the large study size, we were not able to perform fully adjusted analyses for stillbirth because of too few exposed cases.

\section{Clinical implications and conclusion}

Women with epilepsy who take antiepileptic drugs during pregnancy had no increased risk of spontaneous abortion. We had limited data to study still birth, but the overall and absolute risk was low. The data support that pregnant women with epilepsy can continue antiepileptic drug treatment as the risk of fetal death is low. However, our study indicates that women with epilepsy treated with a high dose of antiepileptic drug might have an increased risk of spontaneous abortion, especially when using high doses of valproate, clonazepam, and carbamazepine.

Our study supports the view that antiepileptic drug treatment in pregnancy should aim at the lowest possible dose, but also bearing in mind that antiepileptic drug treatment in pregnancy is associated with potential harmful effects on the developing fetus, including congenital malformations and adverse effects on neurodevelopment.

Contributors: BHB, MISK, MJS, JO, ETP, LHP, MV, and JC conceived and designed the study. LHP and JC acquired the data. All authors contributed to the analyses and interpretation of data and drafting the manuscript. BHB is guarantor.

Funding: $\mathrm{JC}$ receives research support from the Danish Epilepsy Association. LHP is supported by a Sapere Aude-Postdoc grant from the Danish Council for Independent Research. The funding sources had no role in the design and conduct of the study; the collection, analysis and interpretation of data; or the preparation, review, or approval of the manuscript.

Competing interests: All authors have completed the ICMJE uniform disclosure form at www.icmje.org/coi_disclosure.pdf and declare: no support from any organisation for the submitted work; JC received honorariums for giving lectures and serving on the scientific advisory board of UCB Nordic and Eisai, and received funding for a trip from UCB Nordic; no other relationships or activities that could appear to have influenced the submitted work.

Ethical approval: This study was approved by the Danish Data Protection Agency. Ethical approval was not required as this was a registry study.

Data sharing: No additional data available.
Transparency: The lead author (BHB) affirms that this manuscript is an honest, accurate and transparent account of the study being reported and that no aspects have been omitted.

1 Borthen I, Eide MG, Veiby G, Daltveit AK, Gilhus NE. Complications during pregnancy in women with epilepsy: population-based cohort study. BJOG 2009;116:1736-42.

2 Hauser WA, Annegers JF, Rocca WA. Descriptive epidemiology of epilepsy: contributions of population-based studies from Rochester, Minnesota. Mayo Clin Proc 1996;71:576-86.

3 Schmidt D, Schachter SC. Drug treatment of epilepsy in adults. BMJ 2014;348:g254.

4 Bobo WV, Davis RL, Toh S, Li DK, Andrade SE, Cheetham TC, et al. Trends in the use of antiepileptic drugs among pregnant women in the US, 2001-2007: a medication exposure in pregnancy risk evaluation program study. Paediatr Perinat Epidemiol 2012;26:578-88.

5 Christensen J, Gronborg TK, Sorensen MJ, Schendel D, Parner ET, Pedersen LH, et al. Prenatal valproate exposure and risk of autism spectrum disorders and childhood autism. JAMA 2013;309:1696-703.

6 Borthen I, Gilhus NE. Pregnancy complications in patients with epilepsy. Curr Opin Obstet Gynecol 2012;24:78-83.

7 Padmanabhan R, Abdulrazzaq YM, Bastaki SM, Nurulain M, Shafiullah M. Vigabatrin (VGB) administered during late gestation lowers maternal folate concentration and causes pregnancy loss, fetal growth restriction and skeletal hypoplasia in the mouse. Reprod Toxicol 2010;29:366-77.

8 Padmanabhan R, Abdulrazzaq YM, Bastaki SM, Shafiullah M, Chandranath SI. Experimental studies on reproductive toxicologic effects of lamotrigine in mice. Birth Defects Res B Dev Reprod Toxicol 2003;68:428-38.

9 Thomas SV, Sindhu K, Ajaykumar B, Sulekha Devi PB, Sujamol J. Maternal and obstetric outcome of women with epilepsy. Seizure 2009;18:163-6.

10 Richmond JR, Krishnamoorthy P, Andermann E, Benjamin A. Epilepsy and pregnancy: an obstetric perspective. Am J Obstet Gynecol 2004;190:371-9.

11 Ornoy A, Zvi N, Arnon J, Wajnberg R, Shechtman S, Diav-Citrin O. The outcome of pregnancy following topiramate treatment: a study on 52 pregnancies. Reprod Toxicol 2008;25:388-9.

12 Meador KJ, Baker GA, Finnell RH, Kalayjian LA, Liporace JD, Loring DW, et al. In utero antiepileptic drug exposure: fetal death and malformations. Neurology 2006;67:407-12.

13 Speidel BD, Meadow SR. Maternal epilepsy and abnormalities of the fetus and newborn. Lancet 1972;2:839-43.

14 Annegers JF, Baumgartner KB, Hauser WA, Kurland LT. Epilepsy, antiepileptic drugs, and the risk of spontaneous abortion. Epilepsia 1988;29:451-8.

15 Kulaga S, Sheehy O, Zargarzadeh AH, Moussally K, Berard A. Antiepileptic drug use during pregnancy: perinatal outcomes. Seizure 2011;20:667-72.

16 Pedersen CB, Gotzsche H, Moller JO, Mortensen PB. The Danish Civil Registration System. A cohort of eight million persons. Dan Med Bull 2006;53:441-9.

17 Knudsen LB, Olsen J. The Danish Medical Birth Registry. Dan Med Bull 1998;45:320-3.

18 Andersen TF, Madsen M, Jorgensen J, Mellemkjoer L, Olsen JH. The Danish National Hospital Register. A valuable source of data for modern health sciences. Dan Med Bull 1999:46:263-8.

19 WHO Collaborating Centre for Drug Statistics Methodology (WHOCC). Defined daily dose; definition and general considerations. 2013. www.whocc.no/ddd.

20 Mors O, Perto GP, Mortensen PB. The Danish Psychiatric Central Research Register. Scand J Public Health 2011;39(7 Suppl):54-7.

21 Nakane $Y$, Okuma T, Takahashi R, Sato $Y$, Wada T, Sato T, et al. Multi-institutional study on the teratogenicity and fetal toxicity of antiepileptic drugs: a report of a collaborative study group in Japan. Epilepsia 1980;21:663-80

22 EURAP Study Group. Seizure control and treatment in pregnancy: observations from the EURAP epilepsy pregnancy registry. Neurology 2006;66:354-60.

23 Mawhinney E, Campbell J, Craig J, Russell A, Smithson W, Parsons L, et al. Valproate and the risk for congenital malformations: is formulation and dosage regime important? Seizure 2012;21:215-8.

24 Tomson T, Battino D, Bonizzoni E, Craig J, Lindhout D, Sabers A, et al. Dose-dependent risk of malformations with antiepileptic drugs: an analysis of data from the EURAP epilepsy and pregnancy registry. Lancet Neurol 2011;10:609-17.

25 Diav-Citrin O, Shechtman S, Bar-Oz B, Cantrell D, Arnon J, Ornoy A. Pregnancy outcome after in utero exposure to valproate : evidence of dose relationship in teratogenic effect. CNS Drugs 2008:22:325-34.

26 Olesen C, Sondergaard C, Thrane N, Nielsen GL, de Jong-van den Berg, Olsen J. Do pregnant women report use of dispensed medications? Epidemiology 2001;12:497-501.

27 Lohse SR, Farkas DK, Lohse N, Skouby SO, Nielsen FE, Lash TL, et al. Validation of spontaneous abortion diagnoses in the Danish National Registry of Patients. Clin Epidemiol 2010;2:247-50.

Accepted: 3 August 2014

\section{Cite this as: BMJ 2014;349:95159}

This is an Open Access article distributed in accordance with the Creative Commons Attribution Non Commercial (CC BY-NC 3.0) license, which permits others to distribute, remix, adapt, build upon this work non-commercially, and license their derivative works on different terms, provided the original work is properly cited and the use is non-commercial. See: http://creativecommons.org/licenses/by-nc/3.0/. 


\section{What is already known on this topic}

Studies have found an association between the use of antiepileptic drugs during pregnancy and congenital malformation Little is known about the association between use of antiepileptic drugs during pregnancy and the risk of spontaneous abortion and still birth

\section{What this study adds}

Our large, registry based study suggests that women treated for epilepsy with antiepileptic drugs during pregnancy may not be at increased risk of spontaneous abortion

We could not identify an association between antiepileptic drug use and stillbirth, but the numbers analysed were small

\section{Tables}

\section{Table 1 Characteristics of eligible pregnancies}

\begin{tabular}{|c|c|c|}
\hline \multirow[b]{2}{*}{ Characteristics } & \multicolumn{2}{|c|}{ No $(\%)$} \\
\hline & Using antiepileptics $(n=4700)$ & $\begin{array}{l}\text { Not using antiepileptics } \\
\qquad(\mathrm{n}=978605)\end{array}$ \\
\hline \multicolumn{3}{|c|}{ Maternal age at conception (years): } \\
\hline$<21$ & $280(6.0)$ & $55535(5.7)$ \\
\hline $21-25$ & $784(16.7)$ & $155703(15.9)$ \\
\hline $26-30$ & $1484(31.6)$ & $333391(34.1)$ \\
\hline $31-35$ & $1374(29.2)$ & $290464(29.7)$ \\
\hline$\geq 36$ & $778(16.6)$ & $143511(14.7)$ \\
\hline Missing & $0(0.0)$ & $1(0.0)$ \\
\hline \multicolumn{3}{|l|}{ Cohabitation: } \\
\hline Yes & $3244(69.0)$ & $754687(77.1)$ \\
\hline No & $1436(30.6)$ & $215216(22.0)$ \\
\hline Missing & $20(0.4)$ & $8702(0.9)$ \\
\hline \multicolumn{3}{|l|}{ Income (fifths): } \\
\hline First (lowest) & $1130(24.0)$ & $193300(19.8)$ \\
\hline Second & $1280(27.2)$ & $195440(20.0)$ \\
\hline Third & $957(20.4)$ & $195989(20.0)$ \\
\hline Fourth & $778(16.6)$ & $196379(20.1)$ \\
\hline Fifth (highest) & $555(11.8)$ & $196348(20.1)$ \\
\hline Missing & $0(0.0)$ & $1149(0.1)$ \\
\hline \multicolumn{3}{|l|}{ Education (years): } \\
\hline$<10$ & $828(17.6)$ & $107387(11.0)$ \\
\hline $10-12$ & $1782(37.9)$ & $303302(31.0)$ \\
\hline$>12$ & $1970(41.9)$ & $539611(55.1)$ \\
\hline Missing & $120(2.6)$ & $28305(2.9)$ \\
\hline \multicolumn{3}{|c|}{ Maternal psychiatric history: } \\
\hline Yes & $1213(25.8)$ & $61335(6.3)$ \\
\hline No & $3487(74.2)$ & $917270(93.7)$ \\
\hline Missing & $0(0.0)$ & $0(0.0)$ \\
\hline \multicolumn{3}{|c|}{ Maternal history of substance misuse: } \\
\hline Yes & $257(5.5)$ & $5263(0.5)$ \\
\hline No & $4443(94.5)$ & $973342(99.5)$ \\
\hline Missing & $0(0.0)$ & $0(0.0)$ \\
\hline \multicolumn{3}{|c|}{ Maternal history of severe psychiatric disorder: } \\
\hline Yes & $253(5.4)$ & $2439(0.2)$ \\
\hline No & $4447(94.6)$ & $976166(99.8)$ \\
\hline Missing & $0(0.0)$ & $0(0.0)$ \\
\hline
\end{tabular}


Table 1 (continued)

\begin{tabular}{lcc} 
& \multicolumn{2}{c}{ No (\%) } \\
\cline { 2 - 3 } Characteristics & Not using antiepileptics \\
Concurrent drug use: & $(\mathbf{n = 9 7 8 ~ 6 0 5 )}$ \\
\hline Any & $4700(100.0)$ & $617424(63.1)$ \\
\hline Antipsychotics & $364(7.7)$ & $2740(0.3)$ \\
\hline Antidepressants & $752(16.0)$ & $21000(2.1)$ \\
\hline Insulin & $42(0.9)$ & $4537(0.5)$ \\
\hline Induced abortion (reason): & $22(0.5)$ & $2,987(0.3)$ \\
\hline Fetal disease & $1116(23.7)$ & $171569(17.5)$ \\
\hline Other & $1138(24.2)$ & $174556(17.8)$ \\
\hline Combined & & \\
\hline
\end{tabular}


Table 2| Association between antiepileptic drug use during pregnancy and spontaneous abortion and stillbirth

\begin{tabular}{|c|c|c|c|c|}
\hline \multirow{2}{*}{$\begin{array}{l}\text { Antiepileptic use by pregnancy } \\
\text { outcome }\end{array}$} & \multirow[b]{2}{*}{ No of pregnancies } & \multirow[b]{2}{*}{ No of outcomes } & \multicolumn{2}{|c|}{ Risk ratio $(95 \% \mathrm{Cl})$} \\
\hline & & & Crude & Adjusted* \\
\hline \multicolumn{5}{|l|}{ Spontaneous abortion: } \\
\hline Antiepileptics & 3432 & 549 & 1.20 (1.11 to 1.30$)$ & 1.13 (1.04 to 1.22$)$ \\
\hline No antiepileptics & 819507 & 109251 & 1 (reference) & 1 (reference) \\
\hline \multicolumn{5}{|l|}{ Stillbirth: } \\
\hline Antiepileptics & 3081 & 18 & 1.29 (0.80 to 2.10$)$ & NA \\
\hline No antiepileptics & 710058 & 3204 & 1 (reference) & NA \\
\hline
\end{tabular}

$\mathrm{NA}=$ not applicable (owing to too few exposed stillbirths).

*Adjusted for maternal age, cohabitation, income, education, history of severe mental disorder, and history of drug misuse. A total of 802680 participants were included in this analysis. 
Table 3| Association between antiepileptic drug use during pregnancy, and spontaneous abortion stratified on epilepsy diagnosis in mother

\begin{tabular}{|c|c|c|c|c|}
\hline \multirow[b]{2}{*}{ Antiepileptic use by epilepsy diagnosis } & \multirow[b]{2}{*}{ No of pregnancies } & \multirow[b]{2}{*}{ No of spontaneous abortions } & \multicolumn{2}{|c|}{ Risk ratio $(95 \% \mathrm{Cl})$} \\
\hline & & & Crude & Adjusted $^{*}$ \\
\hline \multicolumn{5}{|l|}{ Ever diagnosist: } \\
\hline Antiepileptics & 2615 & 372 & $0.97(0.86$ to 1.08$)$ & 0.98 (0.87 to 1.09$)$ \\
\hline No antiepileptics & 6645 & 978 & 1 (reference) & 1 (reference) \\
\hline \multicolumn{5}{|l|}{ Never diagnosisł: } \\
\hline Antiepileptics & 817 & 177 & $1.63(1.43$ to 1.85$)$ & 1.30 (1.14 to 1.49$)$ \\
\hline No antiepileptics & 812862 & 108273 & 1 (reference) & 1 (reference) \\
\hline \multicolumn{5}{|l|}{ Diagnosis within 5 years of index pregnancy§: } \\
\hline Antiepileptics & 2519 & 344 & $0.90(0.78$ to 1.03$)$ & 0.94 (0.81 to 1.08$)$ \\
\hline No antiepileptics & 2388 & 364 & 1 (reference) & 1 (reference) \\
\hline \multicolumn{5}{|c|}{ No diagnosis within 5 years of index pregnancy $\mathbb{1}$ : } \\
\hline Antiepileptics & 913 & 205 & $1.68(1.49$ to 1.90$)$ & $1.37(1.21$ to 1.54$)$ \\
\hline No antiepileptics & 817119 & 108887 & 1 (reference) & 1 (reference) \\
\hline
\end{tabular}

*Adjusted for maternal age, cohabitation, income, education, history of severe mental disorder, and history of drug misuse.

†Adjusted analysis includes 9116 participants.

$\ddagger$ Adjusted analysis includes 793564 participants.

$\S$ Adjusted analysis includes 4808 participants.

IAdjusted analysis includes 797872 participants. 
Table 4| Association between use of specific antiepileptic drugs during pregnancy and spontaneous abortion, stratified on epilepsy diagnosis in mother

\begin{tabular}{|c|c|c|c|c|}
\hline \multirow[b]{2}{*}{ Antiepileptic by epilepsy diagnosis } & \multirow[b]{2}{*}{ Total No } & \multirow[b]{2}{*}{ No (\%) of spontaneous abortions } & \multicolumn{2}{|c|}{ Relative risk (95\% Cl) } \\
\hline & & & Crude & Adjusted $^{*}$ \\
\hline \multicolumn{5}{|l|}{ Carbamazepine } \\
\hline \multicolumn{5}{|l|}{ Ever epilepsy: } \\
\hline Yes & 409 & $59(14.4)$ & 0.98 (0.77 to 1.25$)$ & 0.96 (0.75 to 1.22$)$ \\
\hline No & 6645 & $978(14.7)$ & 1 (reference) & 1 (reference) \\
\hline \multicolumn{5}{|l|}{ Never epilepsy: } \\
\hline Yes & 95 & $20(21.1)$ & 1.58 (1.07 to 2.33$)$ & NA \\
\hline No & 812862 & $108273(13.3)$ & 1 (reference) & 1 (reference) \\
\hline \multicolumn{5}{|l|}{ Clonazepam } \\
\hline \multicolumn{5}{|l|}{ Ever epilepsy: } \\
\hline Yes & 230 & $31(13.5)$ & 0.92 (0.66 to 1.28$)$ & 0.88 (0.63 to 1.23$)$ \\
\hline No & 6645 & $978(14.7)$ & 1 (reference) & 1 (reference) \\
\hline \multicolumn{5}{|l|}{ Never epilepsy: } \\
\hline Yes & 219 & $60(27.4)$ & 2.06 (1.65 to 2.56$)$ & 1.91 (1.54 to 2.37$)$ \\
\hline No & 812862 & $108273(13.3)$ & 1 (reference) & 1 (reference) \\
\hline \multicolumn{5}{|l|}{ Lamotrigine } \\
\hline \multicolumn{5}{|l|}{ Ever epilepsy: } \\
\hline Yes & 1128 & $153(13.6)$ & 0.92 (0.78 to 1.08$)$ & 0.92 (0.78 to 1.08$)$ \\
\hline No & 6645 & $978(14.7)$ & 1 (reference) & 1 (reference) \\
\hline \multicolumn{5}{|l|}{ Never epilepsy: } \\
\hline Yes & 234 & $47(20.1)$ & 1.51 (1.17 to 1.95$)$ & 1.40 (1.08 to 1.81$)$ \\
\hline No & 812862 & $108273(13.3)$ & 1 (reference) & 1 (reference) \\
\hline \multicolumn{5}{|l|}{ Oxcarbazepine } \\
\hline \multicolumn{5}{|l|}{ Ever epilepsy: } \\
\hline Yes & 413 & $62(15.0)$ & $1.02(0.79$ to 1.31$)$ & 1.00 (0.78 to 1.28$)$ \\
\hline No & 6645 & $978(14.7)$ & 1 (reference) & 1 (reference) \\
\hline \multicolumn{5}{|l|}{ Never epilepsy: } \\
\hline Yes & 38 & $11(28.9)$ & 2.17 (1.35 to 3.50$)$ & NA \\
\hline No & 812862 & $108273(13.3)$ & 1 (reference) & NA \\
\hline \multicolumn{5}{|l|}{ Valproate } \\
\hline \multicolumn{5}{|l|}{ Ever epilepsy: } \\
\hline Yes & 474 & 75 (15.8) & 1.08 (0.88 to 1.32$)$ & 1.05 (0.86 to 1.29$)$ \\
\hline No & 6645 & $978(14.7)$ & 1 (reference) & 1 (reference) \\
\hline \multicolumn{5}{|l|}{ Never epilepsy: } \\
\hline Yes & 58 & $14(24.1)$ & 1.81 (1.16 to 2.82 ) & $\mathrm{NA})$ \\
\hline No & 812862 & $108273(13.3)$ & 1 (reference) & 1 (reference) \\
\hline
\end{tabular}

$\mathrm{NA}=$ not applicable (owing to too few exposed spontaneous abortions).

*Adjusted for maternal age, cohabitation, income, education, history of severe mental disorder, and history of drug misuse. 


\section{Figure}

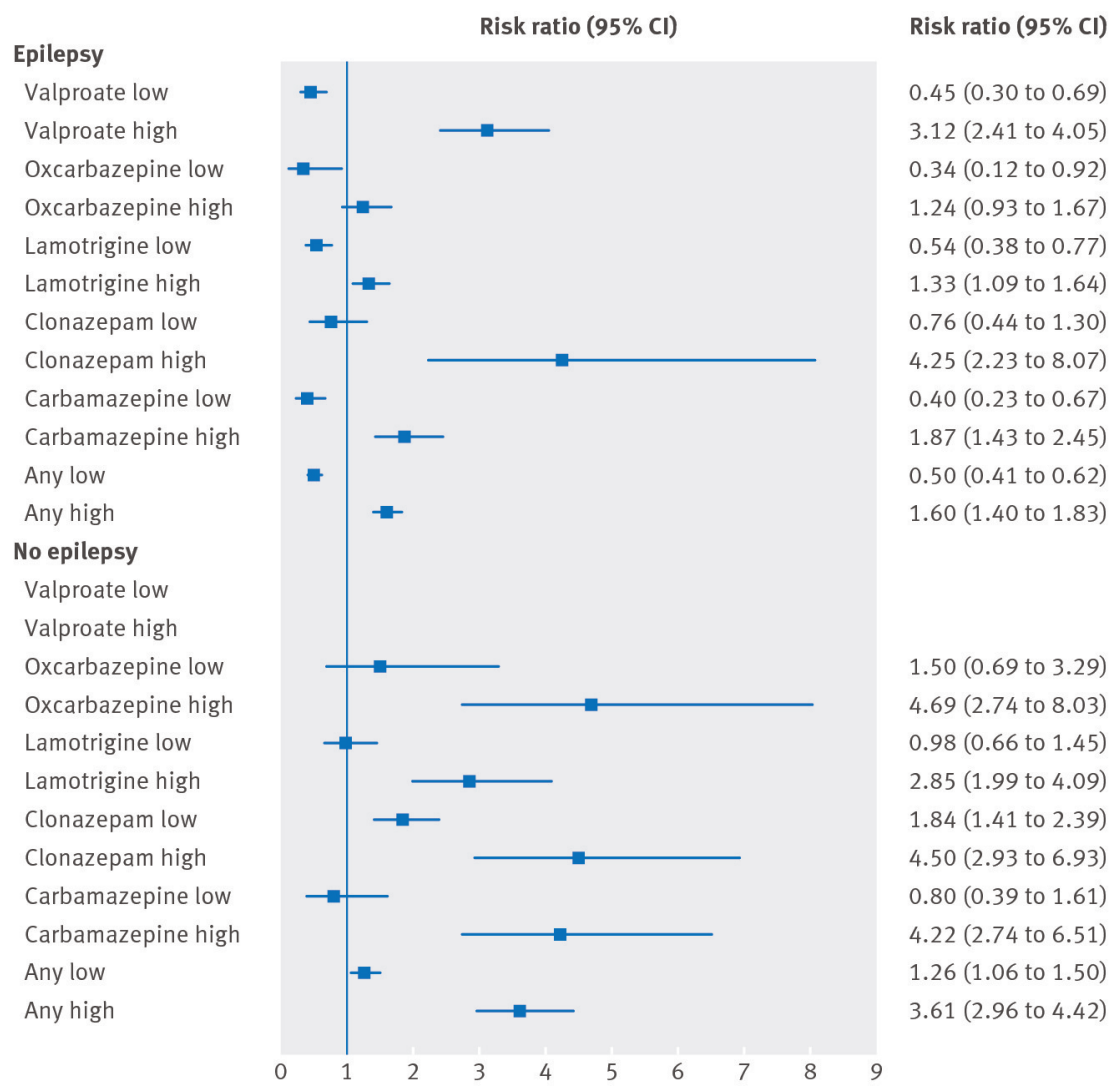

Association between dose of specific antiepileptic and spontaneous abortion, stratified on ever epilepsy diagnosis in mother. Estimates shown are risk ratios (95\% confidence intervals). Owing to sparse data it was not possible to analyse valproate for women without an epilepsy diagnosis. High daily dose for different drugs was defined as: carbamazepine $>500 \mathrm{mg} / \mathrm{day}$, clonazepam $>4 \mathrm{mg} /$ day, lamotrigine $>150 \mathrm{mg} /$ day, oxcarbazepine $>500 \mathrm{mg} /$ day, and valproate $>750 \mathrm{mg} / \mathrm{day}$ 